Original Article

\title{
Elderly-customized hatha yoga effects on the vascular inflammation factors of elderly women
}

\author{
SAngsoo Kim, $\mathrm{PhD}^{1)}$, Sungbum Ju, $\mathrm{PhD}^{2)^{*}}$ \\ 1) Department of Physical Education, Keimyung University, Republic of Korea \\ 2) Department of Sport and Health Care, Namseoul University: 91 Daehak-ro, Seonghwan-eup, \\ Seobuk-gu, Cheonaan-si, Chungcheongnam-do 310-20, Republic of Korea
}

\begin{abstract}
Purpose] The aim of this study was to examine the effects of the application of elderly-customized hatha yoga on the vascular inflammation factors of elderly women. [Subjects and Methods] This research was conducted with 14 elderly women, between 70 and 80 years old, divided into an elderly-customized hatha yoga group $(n=7)$ and a control group $(n=7)$. The application group participated in a hatha yoga program designed to be elderlyfriendly for 10 weeks. At the end of the program, the vascular inflammation factors were measured, including the albumin, white blood cell count, fibrinogen, high sensitivity C-reactive protein (hs-CRP), and erythrocyte sedimentation rate (ESR). [Results] In the hatha yoga group, the albumin increased significantly after the application, when compared to the level before the application, while the fibrinogen, hs-CRP, and ESR decreased significantly. In the control group, the vascular inflammation factor levels before and after the application period were not significantly different. [Conclusion] Based on the results of this study, the application of elderly-customized hatha yoga created positive changes in the vascular inflammation factors of elderly women.

Key words: Elderly-customized hatha yoga, Vascular inflammation factor, Elderly women
\end{abstract}

(This article was submitted Apr. 27, 2017, and was accepted Jun. 20, 2017)

\section{INTRODUCTION}

In senescence, a reduction in muscular strength, musculoskeletal system atrophy, changes in the postural alignment, and balanced gait abnormalities occur naturally. Moreover, cardiovascular diseases, such as coronary artery disease, hypertension, and stroke, can be induced, and the risk of inflammatory diseases increases due to declining immune system functions ${ }^{1)}$. Some researchers have suggested that appropriate exercise can stimulate an elderly person's immune system to maintain and improve immune functions ${ }^{2}$. In addition, it has been reported that regular exercise can play a role in delaying or preventing the aging process, along with boosting the immune system ${ }^{3}$. Other researchers have warned that despite the positive effects of exercising, elderly persons show rapid declines in their physiological functions and physical fitness, increases in their physical fatigue, and rapid declines in their recuperative powers against fatigue. However, inadequate participation in exercise may act as a factor causing oxidative stress and inflammation ${ }^{4)}$.

By emphasizing a harmonious balance between physical, mental, spiritual, and social health ${ }^{5)}$, and using posture and breathing exercises, hatha yoga progresses in the form of maintaining and repeating isometric exercises. This is the act of contracting diverse muscles in fixed poses, creating muscle relaxation. Previous studies have reported its effects in the treatment of musculoskeletal system diseases and arthritis ${ }^{6}$, as well as its improvement in the cardiovascular system, muscular strength, muscular endurance, and neuromuscular function ${ }^{7,8)}$. In addition, one researcher reported that regular aerobic exercise, such as hatha yoga, performed by elderly males brought about an improvement in their immune substances. If these phenomena continue for long periods of time, the defense and attack systems of immunoreactive substances against immune

*Corresponding author. Sungbum Ju (E-mail: accent-ju@nsu.ac.kr)

(C2017 The Society of Physical Therapy Science. Published by IPEC Inc.

(c) (1) $\odot$ This is an open-access article distributed under the terms of the Creative Commons Attribution Non-Commercial No DerivaBY NC ND tives (by-nc-nd) License. (CC-BY-NC-ND 4.0: http://creativecommons.org/licenses/by-nc-nd/4.0/) 
diseases like cancer could be improved ${ }^{9)}$.

Choosing appropriate forms of exercise for elderly individuals should be carefully considered to improve their quality of life and allow them to live out their remaining years in a healthy way. Therefore, the purpose of this study was to develop and apply an elderly-customized form of hatha yoga to investigate the effects of this type of exercise on the vascular inflammation factors in elderly women.

\section{SUBJECTS AND METHODS}

This research was conducted with 14 elderly women, between the ages of 70 and 80 years old, divided into an elderlycustomized hatha yoga group $(\mathrm{n}=7)$ and a control group $(\mathrm{n}=7)$. The mean age of the yoga group was $76.1 \pm 5.4$ years old, with a mean height of $154.9 \pm 7.7 \mathrm{~cm}$ and mean weight of $61.72 \pm 9.3 \mathrm{~kg}$. The mean age of the control group was $78.0 \pm 5.9$ years old, with a mean height of $157.5 \pm 3.6 \mathrm{~cm}$ and a mean weight of $64.0 \pm 13.9 \mathrm{~kg}$. These groups were homogeneous because there was no statistically significant difference between the two groups $(\mathrm{p}<0.05)$. The elderly-customized hatha yoga program consisted of 60 minutes of exercise three times per week for 10 weeks. Five minutes each of joint stretching and breathing in the prayer and corpse yoga poses were performed as the warm-up exercises. The main exercises were elderly-customized modifications of hatha yoga poses. To achieve the elderly-customized exercise intensity, the target heart rates of $30-40 \%$ of the heart rate reserve (HRR) were calculated using the Karvonen formula. The subjects were encouraged to perform the individual hatha yoga poses at $30-40 \%$ of the degrees of completion, and to perform breathing exercises in the prayer and the corpse poses between the individual isometric poses. The major poses used were as follows: sitting forward bend pose, bound angle pose, wide-angle seated forward bend pose, bridge shoulder stand pose, revolved abdomen pose (supine), cobra pose, revolved abdomen pose (prone), cat stretch pose, and plough pose.

The following vascular inflammation variables of the blood were analyzed: albumin, white blood cell (WBC) count, fibrinogen, high sensitivity C-reactive protein (hs-CRP), and erythrocyte sedimentation rate (ESR). For the measured data, paired t-tests were conducted using SPSS 21.0 for Windows to examine the changes between the pre and post-application of the yoga exercises in each group. Significance level $\alpha$ was set to 0.05 . This study has been prepared in accordance with the Namseoul University research ethics standards, and the subjects were safely protected throughout every stage of the experiment. All of the subjects understood the purpose of this study and provided written informed consent prior to their participation in accordance with the ethical standards of the Declaration of Helsinki.

\section{RESULTS}

With regard to the changes in the vascular inflammation factors in the yoga group, the albumin was increased significantly after the application $(\mathrm{p}<0.05)$, while the fibrinogen, hs-CRP, and ESR were significantly decreased. There was no significant difference in the WBC count in the yoga group, but there was a tendency toward a numerical decrease. In the control group, there were no significant differences between the vascular inflammation factor values before and after the application (Table 1).

\section{DISCUSSION}

Age-related vascular diseases are closely related to changes in the albumin, WBC count, hs-CRP, and fibrinogen, which are acute vascular inflammatory factors, since such changes are attributable to the progression of vascular inflammation ${ }^{10)}$. Among the vascular inflammation factors tested in this study, the albumin increased significantly in the yoga group after

Table 1. The comparison of vascular inflammation factors in the each group

\begin{tabular}{llcc}
\hline Group & Vascular inflammation factors & Pre (mean $\pm \mathrm{SD})$ & Post (mean $\pm \mathrm{SD})$ \\
\hline & Albumin $(\mathrm{g} / \mathrm{dl}){ }^{*}$ & $4.4 \pm 0.2$ & $4.7 \pm 0.1$ \\
& WBC $\left(10^{3} / \mathrm{ul}\right)$ & $7.0 \pm 1.8$ & $6.1 \pm 1.3$ \\
ECHYG & Fibrinogen $(\mathrm{mg} / \mathrm{dl}){ }^{*}$ & $331.4 \pm 43.8$ & $302.8 \pm 51.3$ \\
& hs-CRP $(\mathrm{mg} / \mathrm{dl})^{*}$ & $0.12 \pm 0.09$ & $0.07 \pm 0.03$ \\
& ESR $(\mathrm{mm} / \mathrm{hr})^{*}$ & $21.0 \pm 5.3$ & $17.7 \pm 4.0$ \\
& Albumin $(\mathrm{g} / \mathrm{dl})$ & $4.5 \pm 0.3$ & $4.4 \pm 0.2$ \\
& WBC $\left(10^{3} / \mathrm{uL}\right)$ & $5.8 \pm 1.4$ & $6.0 \pm 1.8$ \\
CONG & Fibrinogen $(\mathrm{mg} / \mathrm{dl})$ & $341.4 \pm 27.6$ & $342.9 \pm 23.5$ \\
& hs-CRP $(\mathrm{mg} / \mathrm{dl})$ & $0.09 \pm 0.07$ & $0.14 \pm 0.11$ \\
& ESR $(\mathrm{mm} / \mathrm{hr})$ & $26.42 \pm 6.7$ & $30.8 \pm 17.6$ \\
\hline
\end{tabular}

${ }^{*} \mathrm{p}<0.05$, ECHYG: elderly-customized hatha yoga group; CONG: control group 
the application of the elderly-customized hatha yoga, when compared to those levels before the application. Albumin is a protein biosynthesized in the liver, and it is involved in the maintenance of osmotic pressure, the movement and transport of substances, immunity, and enzyme reactions. If the concentration of albumin decreases, nephrotic syndrome, infectious hepatitis, and/or liver cirrhosis could be present. Regular aerobic exercise has been reported to be helpful for the prevention of cardiovascular diseases in elderly females by preventing a drop in the serum albumin levels and increasing the albumin values to within the normal range.

With regard to physical activity and the vascular inflammatory factors, some researchers have indicated that albumin concentrations significantly increase when the intensity of physical activity increases, improving the levels of both the activities of daily living and overall physical activity ${ }^{11}$. In the present study, the same results were shown along with the significant increase in the albumin values after the application of yoga.

Among the vascular inflammation factors, the fibrinogen, hs-CRP, and ESR levels decreased significantly after the application of the yoga exercises, when compared to those before the application, in the hatha yoga group $(\mathrm{p}<0.05)$. However, although the WBC count exhibited a numerically decreasing trend, there was no significant difference between the pre and post-application values. The hs-CRP plasma protein increases remarkably in cases of inflammatory disease and tissue necrosis. It is also a representative component of the so-called acute phase proteins, which are useful in determining the existence and severity of inflammatory or tissue-disintegrative diseases. Fibrinogen is one factor leading to the formation of thrombi, and increases in the blood concentration of fibrinogen can increase the risks of arteriosclerosis in the cardiovascular system and thrombotic diseases. The ESR can be used to evaluate diverse disease conditions, particularly inflammatory conditions; for example, increases in the ESR are commonly seen in acute and chronic inflammatory conditions in which cytoclasis rapidly increases.

The hatha yoga applied in the present study is traditional yoga used to control physical conditions and train breathing through a balance of mind and body, as achieved by balancing the yin and yang. It is mainly composed of postural methods (called asana poses) and respiratory methods, and has been reported to provide greater aerobic effects than the other types of yoga with regard to the energy consumption ${ }^{12}$. One researcher reported that hatha yoga, jogging, aerobic dance, swimming, and cycling reduce the levels of the vascular inflammatory responses (hs-CRP, fibrinogen, and WBC count) ${ }^{13}$, while another researcher reported that those individuals regularly participating in physical activity had lower fibrinogen concentrations and a greater cellulose solubilizing ability ${ }^{14)}$.

Previous studies have reported that although appropriate exercise improves the blood-clotting process, those with excellent physical fitness had an improved cellulose solubilizing ability and anti-clotting functions when compared to those with poor physical fitness ${ }^{15}$ ). Additionally, when the elderly persons (at least 65 years old) in one study performed aerobic exercise, their serum hs-CRP and ESR values decreased significantly when compared to those before the exercise treatment ${ }^{16)}$. Moreover, those with more physical activity had lower fibrinogen concentrations and a better cellulose solubilizing ability when compared to those with less physical activity ${ }^{17}$. Therefore, it was no surprise that the elderly-customized hatha yoga exercise applied in the present study had positive effects on the vascular inflammatory factors.

High intensity exercise is known to increase the circulation of interleukin-6 (IL-6), which is actively involved in immunoinflammatory responses and the acute inflammatory factors of the blood ${ }^{18)}$. These increases are attributable to the fact that high intensity exercise causes damage to the muscles and increases inflammation in both the joints and muscles. Therefore, when exercise is applied to elderly individuals to create positive changes in the vascular inflammation factors, the intensity of that exercise is especially important. In the present study, the elderly-customized exercise intensity was set when the hatha yoga was applied to induce the results of this research.

In this study, it could be seen that the application of elderly-customized hatha yoga in women aged 70 to 80 years old brought about positive changes in their vascular inflammation factors. The results of this research suggest the benefits of using elderly-customized hatha yoga in those elderly persons suffering from conditions related to poor vascular inflammation factor levels. Although this study was applied to elderly-customized hatha yoga, elderly people should pay attention to physical and psychological burdens and musculoskeletal injuries when applying elderly-customized hatha yoga.

\section{REFERENCES}

1) Bonder BR, Wagner MB: Functional performance in older adults, 3rd ed. Philadelphia: FA. Davis, 2001, pp 74-83.

2) Tvede N, Pedersen BK, Hansen FR, et al.: Effect of physical exercise on blood mononuclear cell subpopulations and in vitro proliferative responses. Scand J Immunol, 1989, 29: 383-389. [Medline] [CrossRef]

3) Jankord R, Jemiolo B: Influence of physical activity on serum IL-6 and IL-10 levels in healthy older men. Med Sci Sports Exerc, 2004, 36: 960-964. [Medline] [CrossRef]

4) Heyward VH: Advanced fitness assessment and exercise prescription. Champaign: Human Kinetics, 2002, pp 124-125.

5) Hauschild T: Yoga between Indo-Aryan nationalism and multi-sited fieldwork. Curr Anthropol, 2007, 48: 463-465. [CrossRef]

6) Greendale GA, McDivit A, Carpenter A, et al.: Yoga for women with hyperkyphosis: results of a pilot study. Am J Public Health, 2002, 92: 1611-1614. [Medline] [CrossRef]

7) Bishop SR: What do we really know about mindfulness-based stress reduction? Psychosom Med, 2002, 64: 71-83. [Medline] [CrossRef] 
8) Kerr K: Relaxation techniques. Crit Rev Phys Rehabil Med, 2000, 12: 51-89. [CrossRef]

9) Bishop MD, Meuleman J, Robinson M, et al.: Influence of pain and depression on fear of falling, mobility, and balance in older male veterans. J Rehabil Res Dev, 2007, 44: 675-683. [Medline] [CrossRef]

10) Abramson B, Derzko C, Lalonde A, et al.: Hormone replacement therapy and cardiovascular disease. J Obstet Gynaecol Can, 2002, 24: 577-582. [Medline] [CrossRef]

11) Ford ES: Does exercise reduce inflammation? Physical activity and C-reactive protein among U.S. adults. Epidemiology, 2002, 13: 561-568. [Medline] [CrossRef]

12) Ray US, Sinha B, Tomer OS, et al.: Aerobic capacity \& perceived exertion after practice of Hatha yogic exercises. Indian J Med Res, 2001, 114: $215-221$. [Medline]

13) King DE, Mainous AG 3rd, Buchanan TA, et al.: C-reactive protein and glycemic control in adults with diabetes. Diabetes Care, 2003, 26: 1535-1539. [Medline] [CrossRef]

14) Szymanski LM, Pate RR: Fibrinolytic responses to me derate intensity exercise, comparision of physically active and inactive men. Thromobsis, 1994, 14: 1740-1750.

15) El-Sayed MS, Sale C, Jones PG, et al.: Blood hemostasis in exercise and training. Med Sci Sports Exerc, 2000, 32: 918-925. [Medline] [CrossRef]

16) Kohut ML, McCann DA, Russell DW, et al.: Aerobic exercise, but not flexibility/resistance exercise, reduces serum IL-18, CRP, and IL-6 independent of betablockers, BMI, and psychosocial factors in older adults. Brain Behav Immun, 2006, 20: 201-209. [Medline] [CrossRef]

17) Rankinen $T$, Rauramaa R, Väisänen $S$, et al.: Inverse relationship between physical activity and plasma fibrinogen in postmenopausal women. Atherosclerosis, 1993, 102: 181-186. [Medline] [CrossRef]

18) Croisier JL, Camus G, Venneman I, et al.: Effects of training on exercise-induced muscle damage and interleukin 6 production. Muscle Nerve, 1999, 22 : 208-212. [Medline] [CrossRef] 